\title{
Mechanism of Supercooled Water Droplet Breakup near the Leading Edge of an Airfoil
}

\author{
Belen Veras-Alba*, José Palacios†, \\ The Pennsylvania State University \\ Mario Vargas $\ddagger$, Charles Ruggeri§ \\ National Aeronautics and Space Administration \\ Glenn Research Center \\ Tadas P. Bartkus *** \\ Ohio Aerospace Institute
}

\begin{abstract}
This work presents the results of an experimental study on supercooled droplet deformation and breakup near the leading edge of an airfoil. The results are compared to prior room temperature droplet deformation results to explore the effects of droplet supercooling. The experiments were conducted in the Adverse Environment Rotor Test $S$ tand (AERTS) at The Penns ylvaniaS State University. An airfoil model placed at the end of the rotor blades mounted onto the hub in the AERTS chamber was moved at speeds ranging between 50 and $80 \mathrm{~m} / \mathrm{sec}$. The temperature of the chamber was set at $-20^{\circ} \mathrm{C}$. A monotonic droplet generator was used to produce droplets that fell from above, perpendicular to the path of the airfoil. The supercooled state of the droplets was determined by measurement of the temperature of the drops at various locations below the droplet generator exit. A temperature prediction code was also used to estimate the temperature of the droplets based on vertical velocity and the distance traveled by droplets from the droplet generator to the airfoil stagnation line. High speed imaging was employed to observe the interaction between the droplets and the airfoil. The high speed imaging provided droplet deformation information as the droplet approached the airfoil near the stagnation line. A tracking software program was used to measure the horizontal and vertical displacement of the droplet against time. It was demons trated that to compare the effects of water supercooling on droplet deformation, the ratio of the slip velocity and the initial droplet velocity must be equal. A case with equal slip velocity to initial velocity ratios was selected for room temperature and supercooled droplet conditions. The airfoil velocity was $60 \mathrm{~m} / \mathrm{s}$ and the slip velocity for both sets of data was $40 \mathrm{~m} / \mathrm{s}$. In these cases, the deformation of the weakly supercooledand warm droplets did not present different trends. The similar behavior for both environmental conditions indicates that water supercooling has no effect on particle deformation for the limited range of the weak supercooling of the droplets tested and the selected impact velocity. The assumption of a constant surface tension value was further supported by the equal trend of the Bond number obtained for supercooled and room temperature droplets.
\end{abstract}

* Res earch Assistant, Aerospace Engineering, 207Engineering Unit C, AIAA Member

$\uparrow$ Assistant Professor, Aerospace Engineering, 229Hammond Building, AIAA Member

$¥$ Aeros pace Engineer, Icing Branch, 21000 Brookpark Road, As sociate Fellow AIAA

$\S$ Aerospace Engineer, Icing Branch, 21000 Brookpark Road

** Senior Research Associate, Icing Branch, 21000 Brookpark Road, AIAA Member 


\section{Nomenclature}

$\begin{array}{ll}\text { avi } & =\text { Audio video interleave movie format } \\ D B K U P 002 & =\text { Designation for Airfoil used in the experiment } \\ I N T A & =\text { Instituto Nacional de Técnica Aeroespacial } \\ \text { LED } & =\text { Light Emitting Diode } \\ \text { Slip Velocity } & =\text { Relative velocity between the droplet and the air: }\left(\mathbf{V}_{\text {droplet }}-\mathbf{V}_{\text {air }}\right)\end{array}$

\section{Introduction}

Aircraft manufacturers have reported in-flight observation of droplet breakup near the wing surfaces of large trans port aircraft ${ }^{1}$. This observation is important for in-flight icing because if large droplets break up before impinging on aircraft surfaces, the smaller droplets that result may not impinge on the airfoil potentially affecting the ice accretion process. If droplet breakup is a factor in the ice accretion process, current ice accretion codes will need to be modified to account for the breakup phenomena.

In 2005 the Federal A viation Adminis tration(FAA) sponsored a computational study by WichitaState University (Tan, Papadakis and Sampath ${ }^{1}$ ) to as sess the effects of aerodynamic forces on water droplets near the leading edge of an airfoil and the leading edges of the slat and flap elements of a high-lift airfoil. Two-dimensional numerical computations of droplet breakup were done using the TAB model in the commercial code FLUENT. The TAB model used inclu ded only vibrational and bag models of breakup. The effects of chord size and droplet diameter were studied for a NACA 0012 geometry for chords of $0.91 \mathrm{~m}$ (3 feet) and $6.1 \mathrm{~m}$ (20 feet) and droplet sizes of 100, 500 and 1000 micrometers. For the case of a 6.1-m (20-foot) chord airfoil, droplet breakup was studied for a three element airfoil high lift system in a landing configuration. The study indicated that droplets may breakup in regions with severe pres sure gradient. For the $0.91-\mathrm{m}$ (3-foot) chord single element airfoil the droplet breakup occurred aft of the leading edge. For the 6.1-m (20-foot) chord single element airfoil the droplet breakup occurred near the stagnation region only. Large droplets were found to be more susceptible to breakup than smaller ones. They found that when droplet breakup occurred near the airfoil surface there was insufficient dis tance between the airfoil wall and the location where the droplet breakup was initiated for the droplets to achieve complete breakup before hitting the airfoil. The trajectory followed by droplets larger than 500 micrometers were "ballistic" in nature. The study pointed out the lack of experimental data in this area and recommended experimental tests to as sess the effects on droplet breakup and breakup modes from the pressure gradient and the relative droplet-g as velocity near the leading edge of an airfoil.

In 2007 the National Aeronautics and Space Administration (NASA) Glenn Research Center and the Instituto Nacional de Técnica Aeroespacial(INTA) in Madrid, Spain, beg an an experimental research program to obtain droplet breakup data on an airfoil configuration. A droplet breakup rotating rig $^{2}$ was designed and built at the INTA installations near Madrid. The first sets of experiments were conducted at low speeds $(15-66 \mathrm{~m} / \mathrm{s})$ in the fall of 2008 . Using the experience gained from the low speed experiment the test rig was modified to attain speeds up to $90 \mathrm{~m} / \mathrm{sec}$. Additional experiments were conducted between 2008 and 2012 for velocities from 50 to 90 meters per second and droplet sizes from 100 to 1800 micrometers $^{3}$. The results allowed the gain of understanding on the phenomena and the behavior of the important parameters. All the experiments were conducted at roomtemperature. Since in in-flight icing the droplets are supercooled, the effect of supercooling was not answered at the time and remained an open research question.

The present work reports the results of a preliminary experiment conducted in the Adverse Environment Rotor Test Stand (AERTS) facility at The Pennsylvania State University to determine the effect of supercooling on droplet deformation and breakup as they approach the leading edge of an airfoil. In the AERTS facility, air temperatures below freezing can be reached and the droplets can be supercooled. An airfoil model placed at the end of the rotating arm was moved at speeds of 50 to $80 \mathrm{~m} / \mathrm{sec}$. A monosize droplet generator produced droplets from 200 to 700 micrometers that were allowed to fall from above, perpendicular to the path of the model airfoil at a given location. The temperature of the facility was maintained at $-20^{\circ} \mathrm{C}$. The droplets were confirmed to be supercooled based on the measurement of the temperature of droplets at various distances from the exit of the droplet generator using an infrared camera. A droplet temperature prediction code was alsoused to verify the supercooling of the droplets based on the environmental conditions, water temperature at the droplet generator, and exit velocity. The prediction tool also confirmed the droplets could be supercooled at the impact location given the conditions provided. High speed imaging

American Institute of Aeronautics and Astronautics 
was employed to observe the droplet deformation and breakup. A tracking software program was used to measure, from the high speed movies, the droplet horizontal and vertical dis placement against time. The horizontal dis placement data was curve fitted to obtain the velocity and acceleration. The velocity and acceleration, together with experimental values of the air velocity at the locations of the droplet, were used to calculate the Weber and Reynolds numbers along the path of the droplet from beginning of deformation to breakup and/or hitting the airfoil. The parameter behavior and the droplet deformation were compared to previous res ults froms tudies done at roomtemperature.

In the present work, for the first time, droplet deformation and breakup has been conducted using supercooled droplets approaching the leading edge of an airfoil. Although preliminary in nature given the complexity of the configuration, the results will help determine the validity of previous studies conducted at room temperature.

\section{Experimental Setup}

The experimental setup has four main elements: the rotating arm unit, the airfoil attached at the end of the am, the monosize droplet generator and the high s peed imaging system. In Figure 1, the conceptual view of the experiment setup with all the elements except the high speed imaging system and the illumination is shown. The experimental setup components in the test cell before a run is presented in Figure 2.

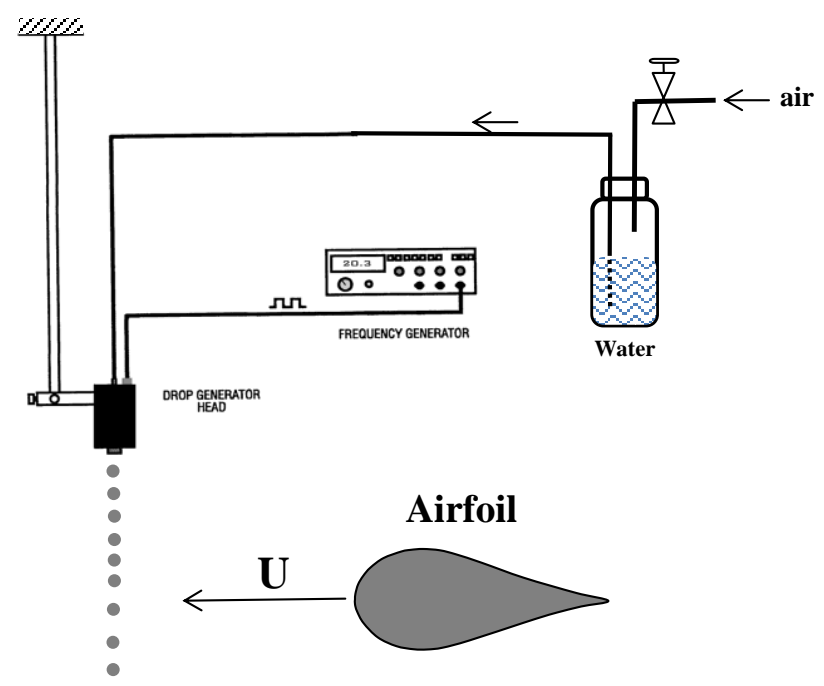

Figure 1: Conceptual view of the experiment. 


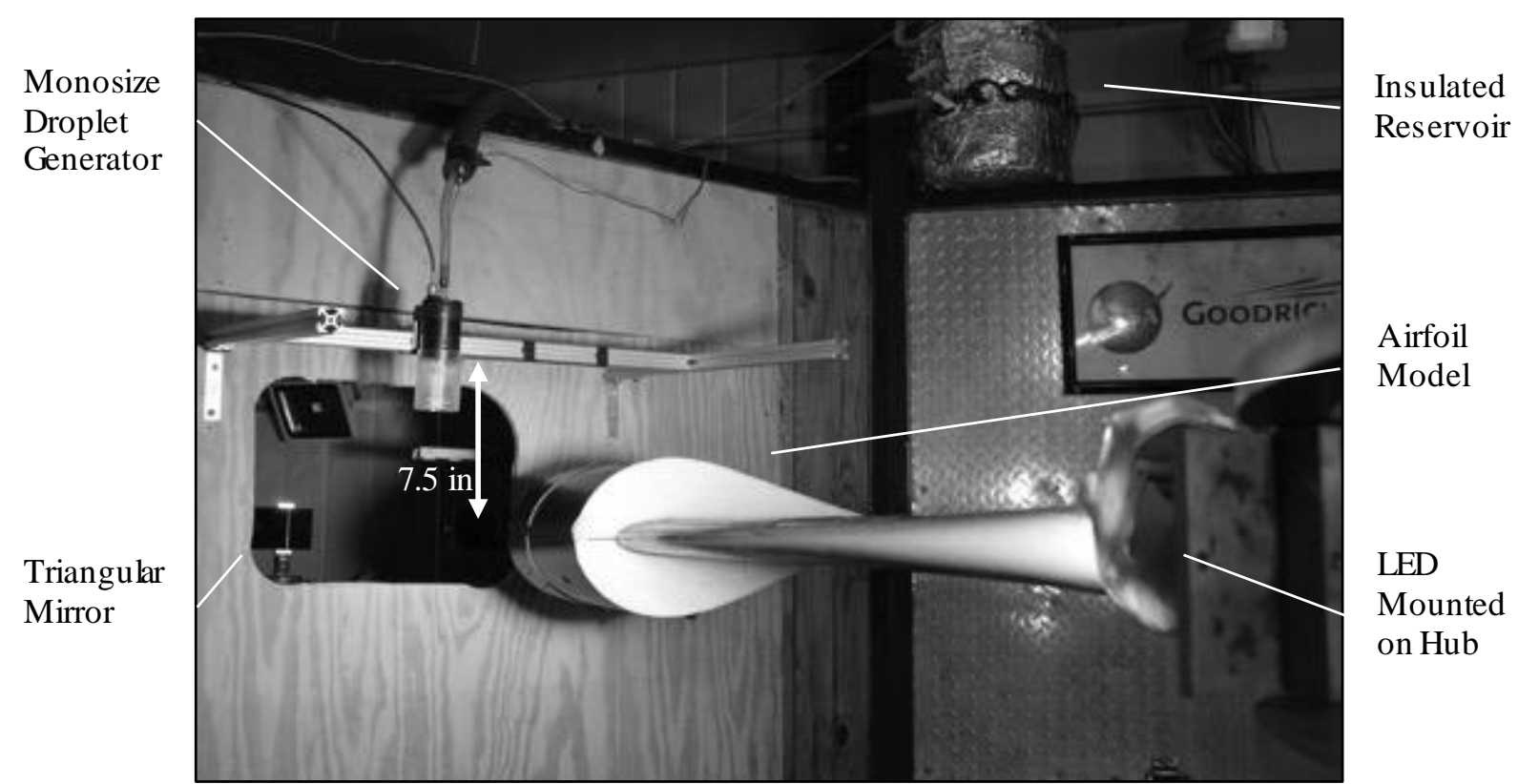

Figure 2: Experimental setup in AERTS facility.

\section{A. The Adverse Environment Rotor Test Stand (AERTS)}

The Adverse Environment Rotor Test Stand (AERTS) facility is located at Penn State University ${ }^{4}$. The facility was designed, and is used to test and evaluate rotorblade ice protection systems. The AERTS facility is also used for ice protection coating evaluation and experimental rotor ice accretion shape correlation to ice shape modeling techniques. The facility is formed by an industrial $6 \mathrm{~m} \times 6 \mathrm{~m} \times 6 \mathrm{~m}(20 \mathrm{ft} \times 20 \mathrm{ft} \times 20 \mathrm{ft})$ cold chamber where temperatures between $-25^{\circ} \mathrm{C}$ and $0^{\circ} \mathrm{C}\left(-13^{\circ} \mathrm{F}\right.$ to $\left.32^{\circ} \mathrm{F}\right)$ can be achieved ${ }^{5}$. The chamber is cooled by convection using cooling lines and a set of fans located inside the chamber. Inside the chamber and surrounding the rotor there is a ballis tic wall in the shape of an octagon. The ballistic wall is formed by $15.2 \mathrm{~cm}(6 \mathrm{in})$ thick weather res is tant lumber reinforced with $0.635 \mathrm{~cm}(0.25 \mathrm{in})$ thick steel and covered by aluminumplating for weather protection. A 93.2 kilowatt $(125 \mathrm{hp})$ motor rotates the hub and the rotors. Figure 3 shows the chamber and its main components as seen from above.

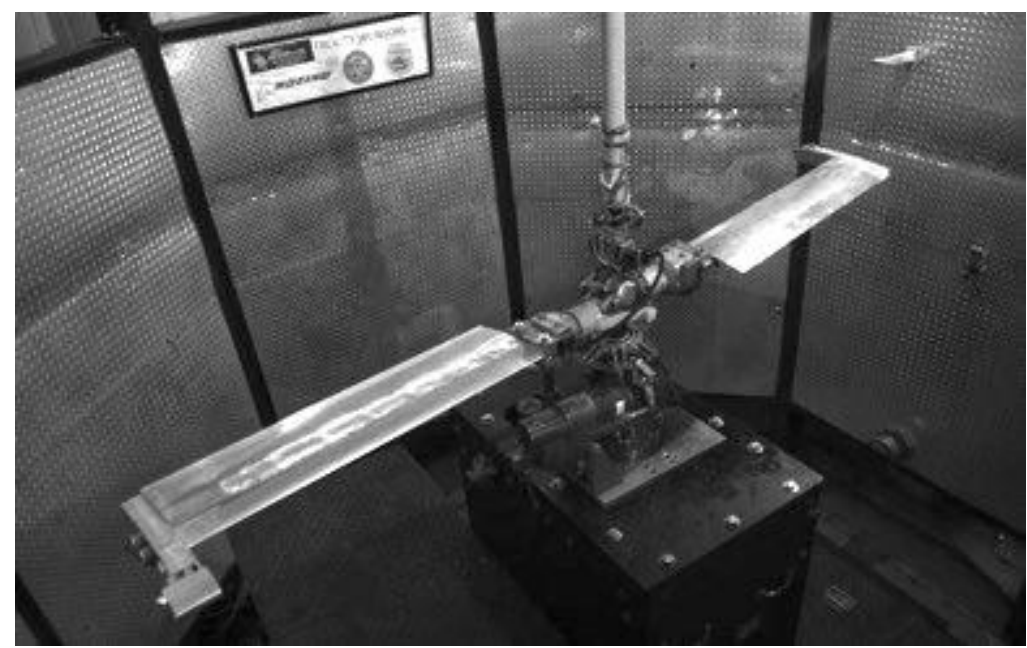

Figure 3: Adverse Environment Rotor Test Stand. 
For the droplet breakup experiment, the AERTS facility was modified to accommodate the high speed visualization of droplet deformation and impact with the airfoil. The imaging system was located behind one of the chamber walls. An opening in the chamber wall allowed the cameras to observe and capture the droplet deformation and impact with the airfoil. A white 9500 lumens High Power LED from Cree was used for illumination. The LED was mounted on the hub of the rotor hub (Figure 4). The airfoils were located at the tip of the rotor blades. The rotor blades were truncated QH-50 fiber-glass blades. The radius of the rotor was $1.57 \mathrm{~m}$ (62 in). During the experiment, the rotor operated from 0 to $501 \mathrm{rpm}$. At the higher rotational speed, the airfoil was traveling at $80 \mathrm{~m} / \mathrm{sec}$.

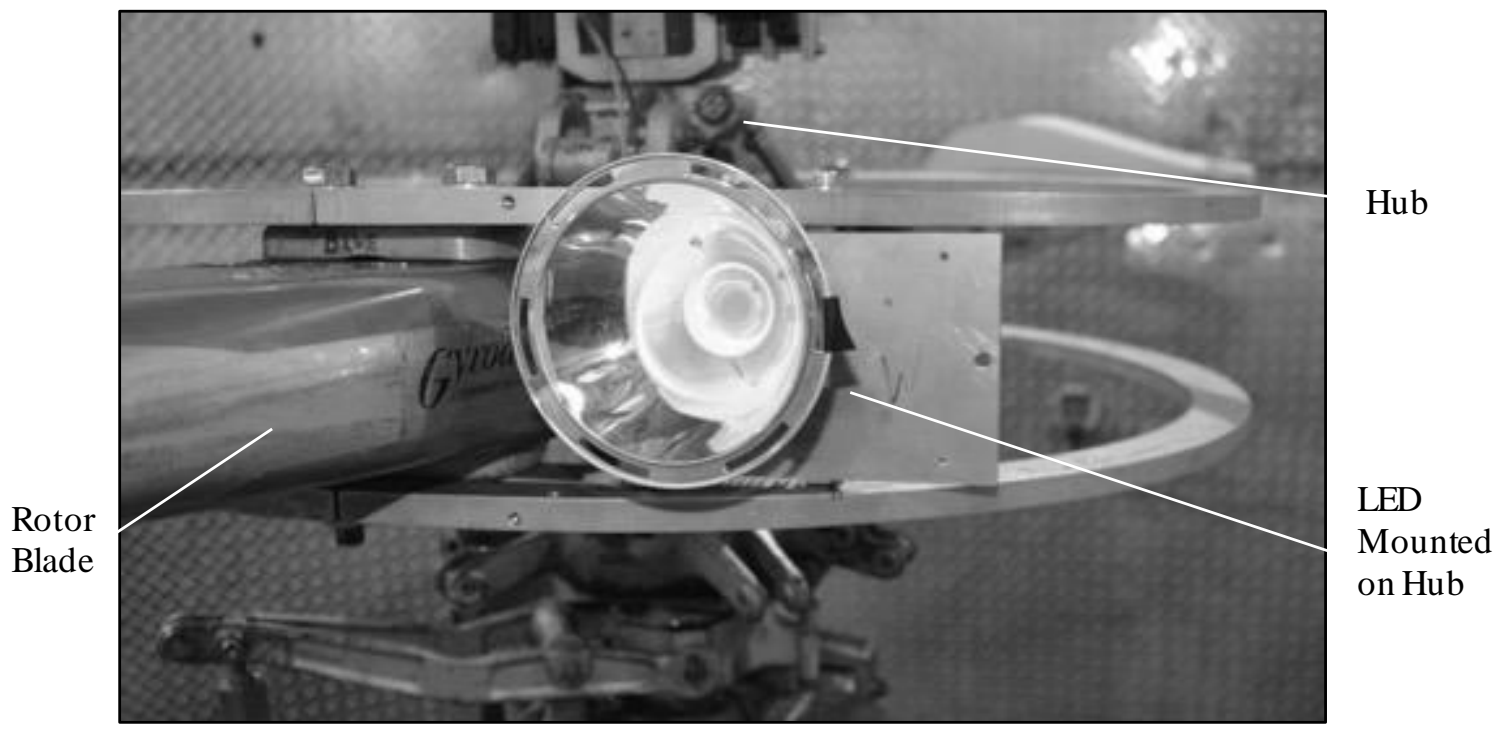

Figure 4: LED mounted on hub

\section{B. Airfoil Model}

The airfoil models mounted at the end of the rotorblades is a generic type of thick airfoil designated as DBKUP 002 (Figure 5). Table 1 lists the coordinates of the airfoil. The airfoil was chosen for the experiment because it has a blunt shape geometry that simulates a scaled version of the type of leading edge shape found on large transport airfoils. The airfoil measures 0.305 meters ( 12 inches) in the spanwise direction, and has a chord length of 0.47 meters (18.5 inches).

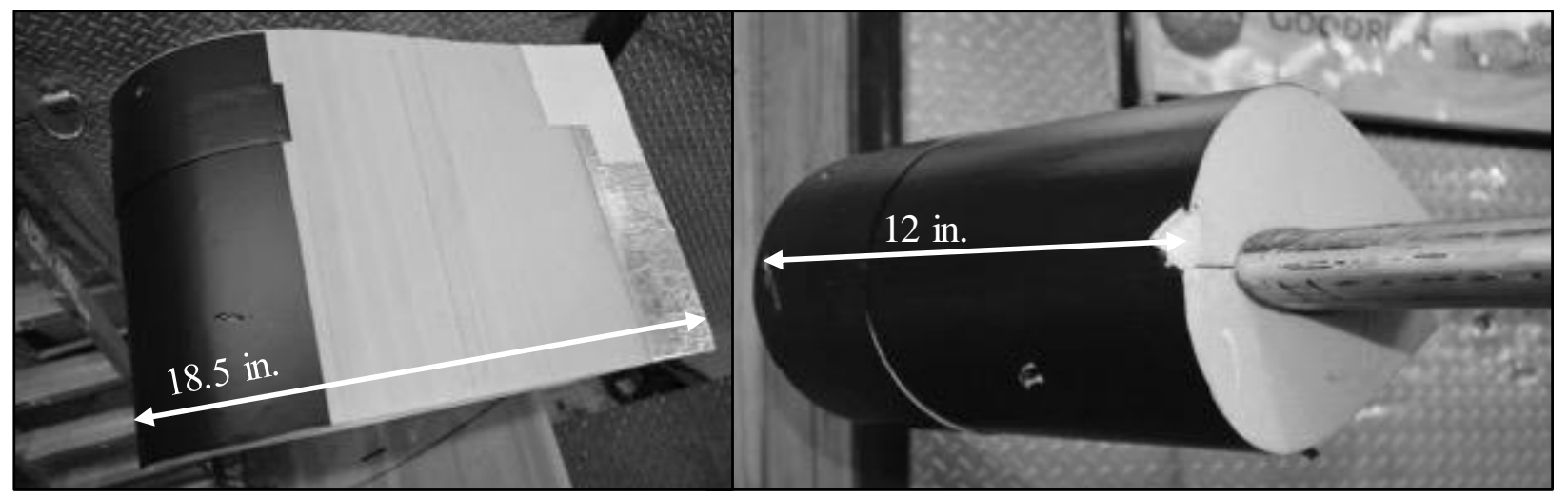

Figure 5: DB KUP 002 airfoil model mounted on QH-50 rotor blade. 


\section{Monosize Droplet Generator}

A TSIMDG-100 Monosize Droplet Generator is us ed to produce water droplets within a diameter range from 100 $\mu \mathrm{m}$ to $500 \mu \mathrm{m}$. The droplet generator (Figure 6) is part of a system containing a water pressure container, a flow control valve, a frequency generator and the vibration head. Air from a compres sor pressurizes the container and generates the water flow from the tank to the vibration head. A high precision flow rate controlvalve with a manometer allows fine adjustment of the flow rate before the water flow reaches the vibration head. At the vibration head the water is forced through a small orifice ( $200 \mu \mathrm{m}$ in diameter) and a jet is formed. A disturbance in the form of a square wave at the appropriate frequency is in troduced by activ ating a piezoelectric transducer controlled with a BK Precision model 4011A frequency generator. The jet is uns table at res onant frequencies and breaks into uniform droplets. For a given orifice diameter, flow rate, and excitation frequency the diameter of the droplets generated is given by equation 1 :

$$
D(\mu m)=317\left[\frac{Q_{(c c / \mathrm{min})}}{f_{(k H z)}}\right]^{1 / 3}
$$

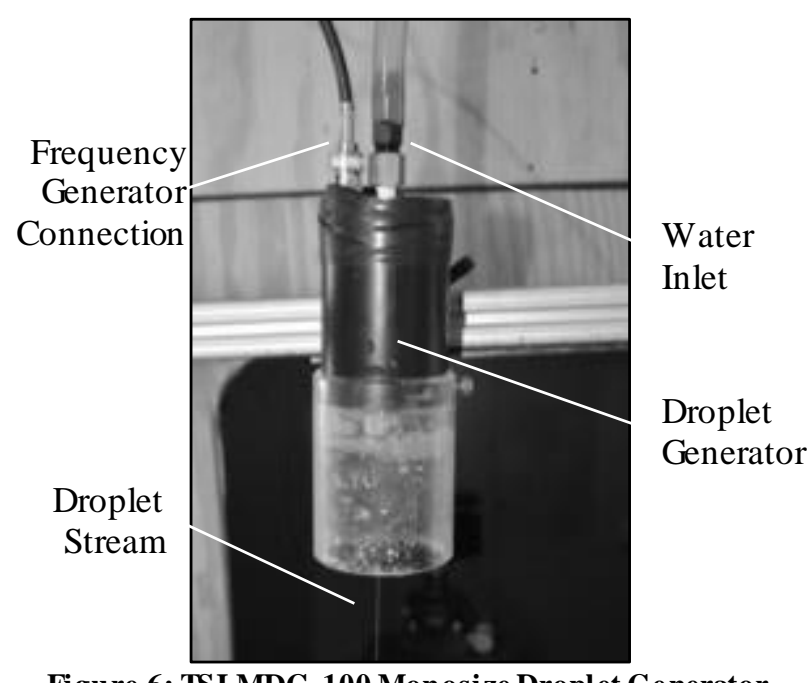

Figure 6: TSI MDG-100 Monosize Droplet Generator.

Where $\mathrm{Q}$ is the water flow rate in cubic centimeters per minute; $\mathrm{f}$ is the frequency in kilohertz; and $\mathrm{D}$ is the diameter of the droplets in micrometers. During the experiment orifices of 200 and $400 \mu \mathrm{m}$ were used. The pressurized container consists of a 5 gallon bucket with an airtight lid. The bucket was insulated and modified to accommodate a bendable immers ion heater as well as the $3.18 \mathrm{~mm}\left(1 / 8^{\text {th }}\right.$ in $)$ OD air hose and tubing for the $12.7 \mathrm{~mm}(1 / 2 \mathrm{in}) \mathrm{OD}, 6.35 \mathrm{~mm}(1 / 4 \mathrm{in})$ ID water hose. The immers ion heater was controlled by a PID controller to power on and off as necessary to maintain the desired water reservoir temperature.

\section{High Speed Imaging System}

The high speed imaging systemconsists of two high-speed cameras, the camera software, a triangular mirror and the lens system(Figure 7). The high-speed cameras used during the experiment were Photron SA-Z. The camera can capture images at rates from 1,000 to $1,000,000$ frames per second (fps). During the experiment a frames rates of 90,000 frames persecond was used. A resolution of $384 \mathrm{Hx} 492 \mathrm{~V}$ pixels was used. The dimensions of the field of view were 11.45 millimeters in the horizontal direction by 14.66 millimeters in the vertical direction. It corres ponded to a resolution of 29.8 micrometers per pixel. The camera software employed for capturing the high speed image sequences is Photron's FASTCAM Viewer (PFV) and is part of the camera system. The same software was used for postprocessing the image sequences to generate the data movies for data analysis. During the experiment one lens configuration on each camera was used for magnification of the droplet deformation and/or breakup. The lens configuration consisted of a $200 \mathrm{~mm}$ Micro Nikkor lens with a $2 x$ doubler added between thecamera and the $200 \mathrm{~mm}$

American Institute of Aeronautics and Astronautics 
lens to double the focal length of the microlens. Both cameras were placed $0.3 \mathrm{~m}(11.88$ inches $)$ fromthe mirror. The distance from the tip of the mirror to the focal plane on the airfoil was $0.7 \mathrm{~m}$ (27.63 inches) (Figure 8). The lightning was designed to illuminate the droplets from behind to create a shadowgraph (black color of the droplets against a white-gray background). The light source was a white 9500 lumens High Power LED from Cree mounted on a ring that was bolted to the blade grips.

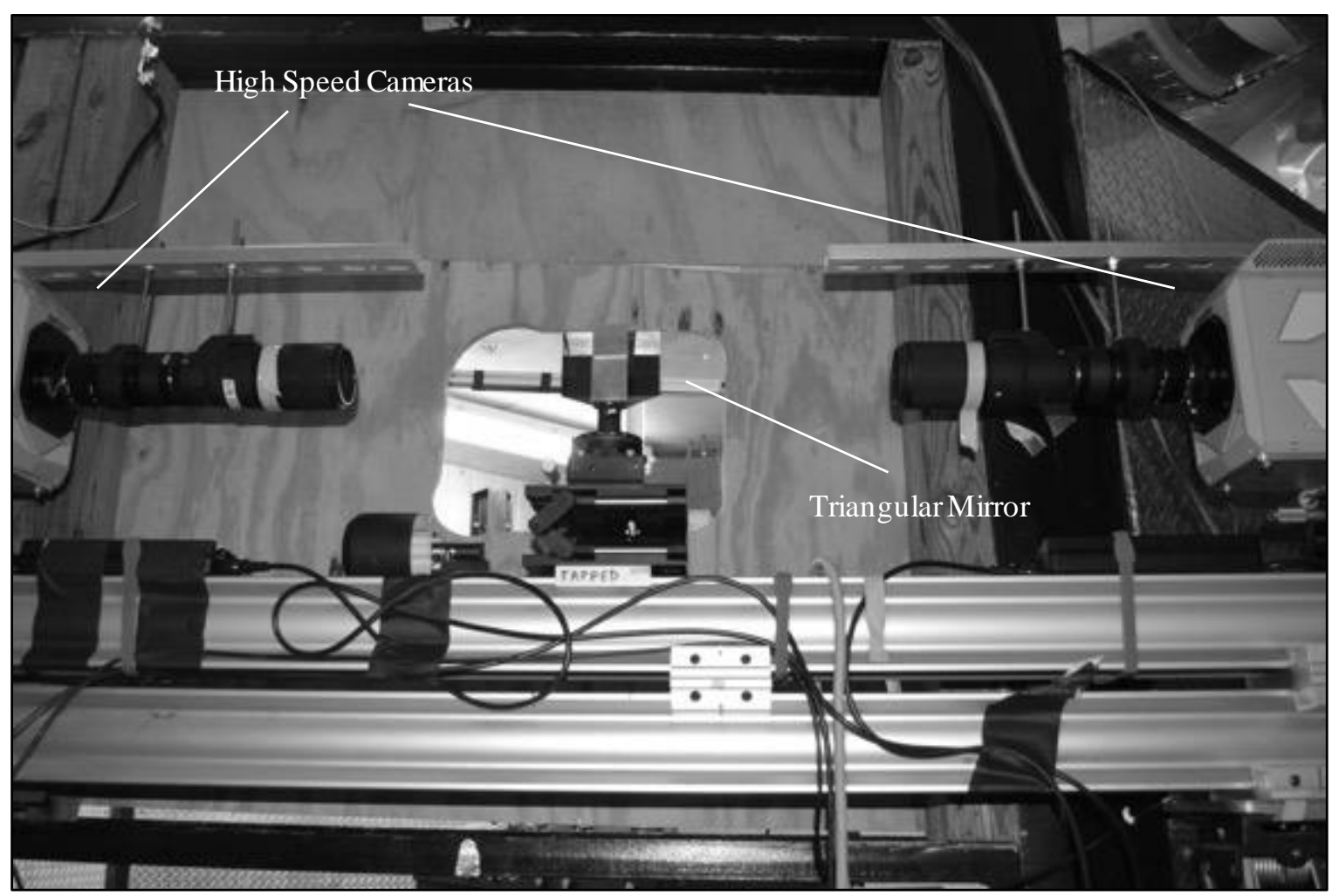

Figure 7: Camera,lens, and triangular mirror setup.

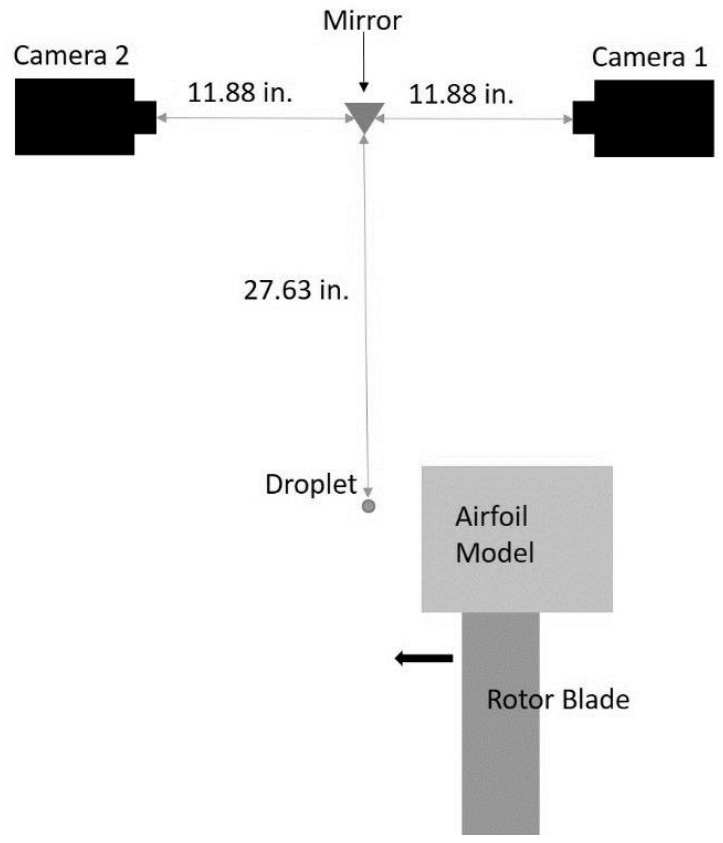

Figure 8: Schematic of top vie w of camera and triangular mirror placement relative to airfoil model and droplet. 


\section{Test Procedure and Test Matrix}

\section{A. Test Procedure}

Before a set of test runs, the high-speed camera system was aligned, so that the line of view of the lens of each camera is parallel with the direction along the span of the airfoil at the midpoint of the leading edge (stagnation line along the s pan). Therotating arm is set at the position, where the falling droplets from the monosize droplet generator will just graze the leading edge. The airfoil is held at the same location during the alignment process. The cameras are placed, with respect to the triangular mirror, at the dis tance required by the optics to obtain the needed magnification and such that the center of the lens depth of field is at the location where the falling droplets graze the airfoil leading edge. The motion of the cameras can be carefully controlled because each camera sits on a steel beamand on an $x-y$ positioning table.

The airfoil is moved from the alignment position and a ruler with the smallest subdivision of one millimeter is placed at the location where the droplets will graze the leading edge of the airfoil. The camera is focused on theruler and the number of pixels per millimeter is recorded, since the number of pixels in the camera sensor and the field of view are known. This conversion is used during the data analy sis to measure the droplet diameter.

The monosize droplet generator controls are adjusted to produce the range of droplet sizes needed. The pressure and the frequency values are read from the calibration table obtained during the previous calibration of the system for the orifice being used in the generator. The pressure valve and the frequency generator are set at the corresponding values and the generatoris started.

The personnel withdraw to the control room, where they are able to observe the motion and operation of the rotor through cameras. The setup cameras are controlled with software run on a laptop computer located in the control room. The software is used to start the camera and set the controlling parameters including the frame rate and the shutter speed. The software allows writing information that will be part of the camera frames. It is located on each frame above the recorded image. This information is helpfulduring the data analysis. During the experiment the following information was recorded on each frame: frame rate, time of recording, image resolution, frame number, lens configuration, date and time, airfoil velocity and targetdroplet size.

The airfoils are set in motion at the revolutions per minute ( $\mathrm{rpm})$ corresponding to the target velocity. When it reaches the target speed, the camera recording is started and maintained for several rotations. Once the recording is completed the rotor is brought to a stop. The high-speed movie is analyzed with the camera software to determine the quality of the recording in each of the passes of the airfoil. If the recording is deemed of good quality the experiment moves to the next test point and the process is repeated.

\section{B. Test Matrix}

The test matrix for the experiment is shown in Table 2. The test matrix was designed to obtain data for rotor tip speeds of $50,60,70$, and $80 \mathrm{~m} / \mathrm{s}$ and for droplet generator orifice sizes of 200 and $400 \mu \mathrm{m}$. The pressure in the reservoir and the frequency of the piezoelectric transducer were varied to obtain the desired droplet sizes when using the different orifices. The higher frame rates of 150000 and $140000 \mathrm{fps}$ were used initially and compared to the lower frame rate of 90000 fps to determine the widest view available with a resolution that allowed for observation of the droplet from no deformation to deformation and breakup. The chamber temperature was maintained above freezing while adjusting the cameras to es tablis $h$ the testing setup. Once the cameras were ready to begin testing, the chamber temperature was decreased to create the environment that would allow the droplets to supercool at the impact location.

\section{Droplet Supercooling Investigation}

Prior to collecting the high-speed video in each test, the temperature of the water is recorded as it exits the reservoir and as it enters the droplet generator. A Type T thermocouple is inserted into the flow at the exit of the reservoir and used with a PID controller connected to the immersed water heater to maintain the water at a constant desired temperature. The water in the reservoir needs to be maintained around $9^{\circ} \mathrm{C}$ to avoid freezing in the water hose and the droplet generator. A thermistor is inserted into the flow at the input of the droplet generator to measure the water

American Institute of Aeronautics and Astronautics 
temperature as close as possible to the droplet jetting location. During the tests, the temperature of the water, after the droplets exited the generator, was not recorded to avoid interfering with the airfoil models .

After the exact location of the droplet generator used in the experiments was established, the setup was repeated without spinning the rotor to measure the temperature of the water at four vertical dis tances from the tip of the droplet generator. The temperature of the water was recorded at 2.54,7.62, 12.7, and $19.05 \mathrm{~cm}(1,3,5$, and 7.5 inches ) below the droplet generator using an infrared (IR) camera and a black surface. The impact of the water droplets against the airfoil occurred at $19.05 \mathrm{~cm}$ ( $7.5 \mathrm{in})$ below the jetting location. The res olution of the IRcamera could not capture the droplets or stream to give a temperature reading. Therefore, a black surface, which was at the chamber temperature of $-20^{\circ} \mathrm{C}$, was used to allow the stream to impact on it allowing the IR camera to provide a temperature reading of the impacting water. The meas urement approach estimates the temperature of the water droplets, but since heat transfer and convective cooling is expected to occur, uncertainty in the measurement exists. In the time between the first contact of the water with the surface and the capturing of the temperature with the camera transient temperature effects occur, since the meas urement does not measure the droplet temperature, but that of the black surface subjected to the warming effect of the supercooled droplets. The mentioned shortcomings related to the meas urement of the water droplet temperature using an infrared camera limits the validity of the datarecorded. Such shortcomings are apparent by the large standard deviation observed on the experimental data, and the unexplained increase in droplet temperature at the $19.05 \mathrm{~cm}$ (7.5 in) location. For this reason, a prediction code ${ }^{6}$ by Tadas P. Bartkus, a NASA Glenn Research Center contractor, was used to further confirm that the droplets were indeed supercooled. The relationship between the droplet temperature in degrees Celsius and the distance from the tip of the droplet generator as indicated by the experimental data and the predictions is dis played in Figure 9. The experimental data suggests that the temperature of the water is below freezing at each point below the tip. The predictions indicate that, while the droplet temperature may not be below freezing 1 inch below the tip, the water droplet temperature decreases to below $0^{\circ} \mathrm{C}$ at the point of impact at $19.05 \mathrm{~cm}$ ( 7.5 inches ) below the tip of the droplet generator for droplets up to almost $700 \mu \mathrm{m}$ in diameter. The diameter of all of the droplets observed was below $700 \mu \mathrm{m}$ and therefore the droplets used in the experiment are supercooled.

The temperature at the tip of the droplet generator of $1^{\circ} \mathrm{C}$ was estimated as the initial droplet temperature in the models because the temperature using the thermistor, located $14.6 \mathrm{~cm}(5.75 \mathrm{in})$ above the tip, read between $2.65^{\circ} \mathrm{C}$ and $4.12^{\circ} \mathrm{C}$. When the temperature at the entry of the dropletgenerator dipped below $2.65^{\circ} \mathrm{C}$, the droplet generator tip would freeze. The temperature of the water is expected to decrease as it travels through the tubing adaptors and the droplet generator which are exposed to the chamber temperature, and given the freezing of the tip observed, the $1^{\circ} \mathrm{C}$ jetting temperature is considered representative.

American Institute of Aeronautics and Astronautics 


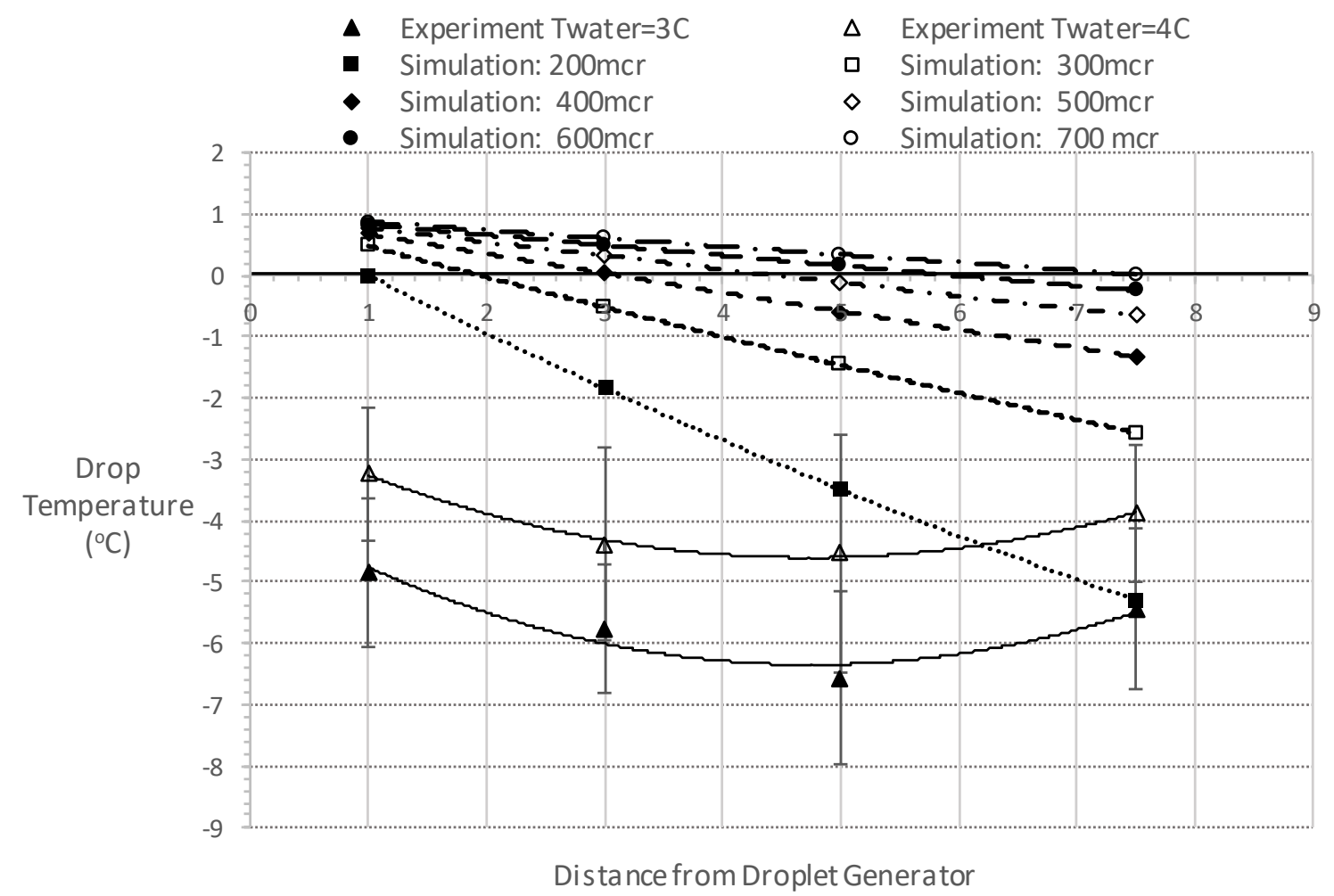

(in)

Figure 9: Droplet temperature at various distances from tip of droplet generator. For simulation purposes, droplet temperature at tip was approximated to be $1^{\circ} \mathrm{C}$, with droplets maintaining a constant vertical velocity of $4 \mathrm{~m} / \mathrm{s}$. Droplet diame ters range from 200 to $700 \mu \mathrm{m}$. Chamber tempe rature is $-20^{\circ} \mathrm{C}$.

\section{Data Analysis}

\section{A. Tracking a Single Droplet to obtain the Droplet Displacement against Time}

The data analy sis is performed using the software program Photron FASTCAM Viewer 3 that allows frame by frame study of the movies, zooming in and out on single frames, running the movies forward and backward, and tracking a single droplet in $x-y$ directions. Using PFV, a high speed movie corresponding to a set of experimental conditions is opened and the frames where the airfoil impacts the droplets are located. There are ten sets of frames per movie that show the airfoil pas sage, becau se during the test, the camera is programmed to capture ten rotations of the airfoil. In general several droplets can be observed impacting the airfoil and, in some cases, breaking up before impact, as shown in Figure 10.
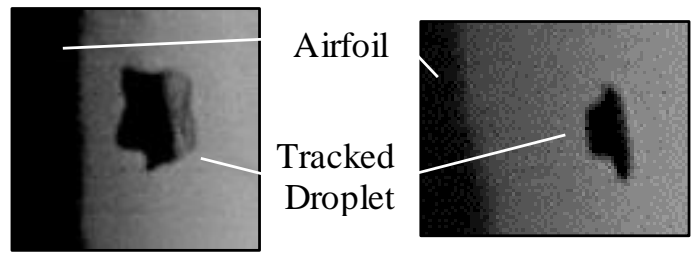

Figure 10: Droplet breakup be fore impact. Chamber temperature $=-20^{\circ} \mathrm{C}$, rotor tip velocity $=80 \mathrm{~m} / \mathrm{s}$, droplet diameter $($ left $)=473 \mu \mathrm{m}$, diameter $($ right $)=401 \mu \mathrm{m}$. 
The movie is run backward and forward to study the behavior of the droplets before and during their interaction with the airfoil. A droplet is selected for study and the programis returned to the frame where the airfo il is about to hit the droplet. The droplet may be deforming or is in the process of breaking up. A copy of the frame is saved in the experimental notes and the droplet to be studied is labeled for future identification. The movie is run backward to the frame where there is no indication of deformation or interaction of the droplet with the approaching airfoil and where the tracking is going to be initiated, an example of both frames is shown in Figure 11. The frames that contain the motion of the droplet and the interaction with the airfoil are separated from the larger set of frames to create a shorter video. This shorter video is saved in .avifile format to be used and processed by a MATLAB program.

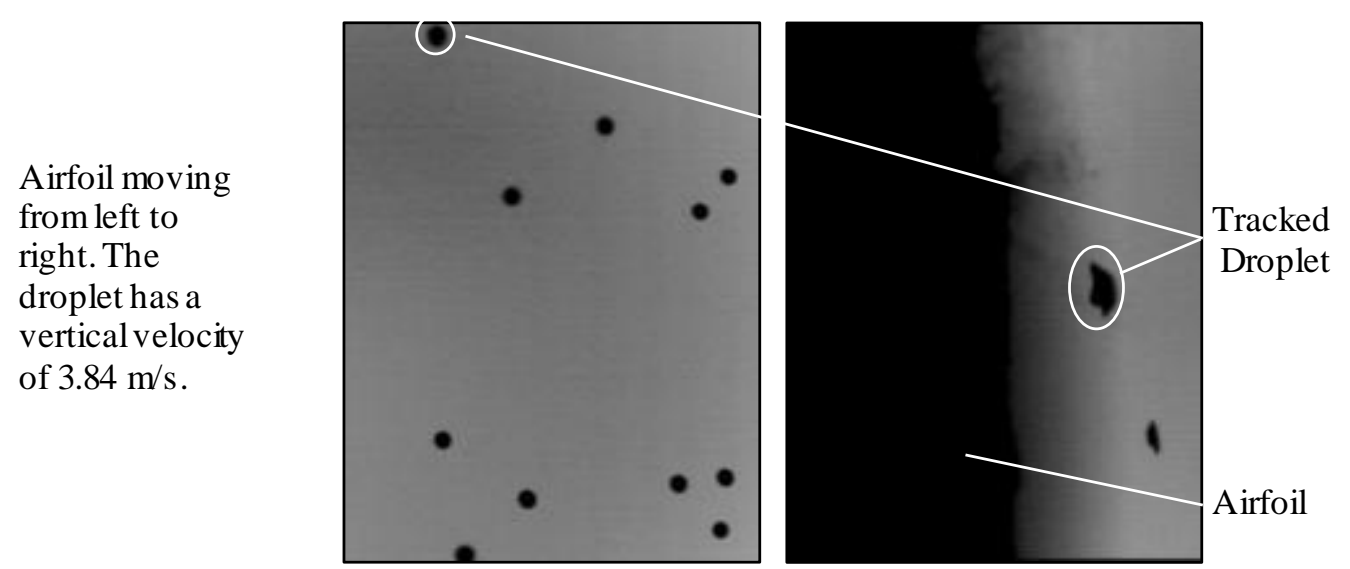

Figure 11: First and last frame of video of a droplet be ing tracked. (Left: droplet tracking begins, Right: droplet tracking ends) Chamber temperature $=-20^{\circ} \mathrm{C}$, rotor tip velocity $=80 \mathrm{~m} / \mathrm{s}$, droplet diameter $=473 \mu \mathrm{m}, 165$ frames in video, 1.83 milliseconds in length.

Once the file is in the correct format and in the file with the MATLAB script, the program requires the frame rate, the number of fames in the video, the droplet number in the first frame (numbering from top to bottom then going left to right, in the case of Figure 11, the droplet to be tracked is droplet number 3 in the frame), the number of the frame where the airfoil first appears, the airfoil velocity, and the resolution to convert from pixels to micrometers. The program begins by verifying the frame numbers and then calculating the appropriate threshold value to convert the grayscale images to binary images using the Otsu method ${ }^{7}$ and prepares the images for the subsequent parts in processing. The programthen determines the number of objects in the images and places an ellipse around the droplet being tracked. The centroid of the ellipse is also calculated and used to determine the motion of the droplet. From the tracking of the centroid, the motion in pixels relative to the first frame is recorded. For each frame, the frame number, the time with res pect to the first frame and the tracking frame, the horizontal and vertical dis placements of the centroid, the area, diameter, and perimeter of the ellipse, and the ellipse major and minor axes lengths are recorded. The information is then used to calculate the droplet velocity and acceleration and the parameters of interest described in the following sections.

\section{B. Calculation of the Horizontal Velocity and Acceleration of the Droplet against Time}

A curve fit of the droplet displacement against time is generated and used to calculate the horizontal velocity and acceleration of the droplet. The data points in the plot are curve-fit with a double five parameter exponential growth equation. The first and second derivatives of the curve-fit equation give the droplet velocity and acceleration. Those are the droplet horizontal velocity and acceleration against time measured by an observer located on a frame of reference at rest with respect to the test cell.

\section{Change from the Frame of Reference at the Test Cell to the Frame of Reference at the Airfoil}

The horizontal displacement, velocity, and acceleration were initially measured in a frame of reference at rest with respect to the test cell. It is more convenient to work in a frame of reference at rest on the airfoil. The frame of reference located on the airfoil has the origin located at the stagnation point on the leading edge. In a strict sense, a frame of coordinates at rest with respect to the airfoil is not an inertial frame because the airfoil is rotating, it is accelerated. Since the interaction between the droplets and the airfoil occurs at a distance less than or equal to the airfoil chord, that section of the airfoil path is nearly straight and the frame of reference at rest with respect to the airfoil is as sumed 
as inertial during that part of its path. The Galilean transformation together with the airfoil velocity was used to convert the velocity and acceleration of the droplet fromthe frame of reference at the test cell to the frame of reference at the airfoil (Figure 12).
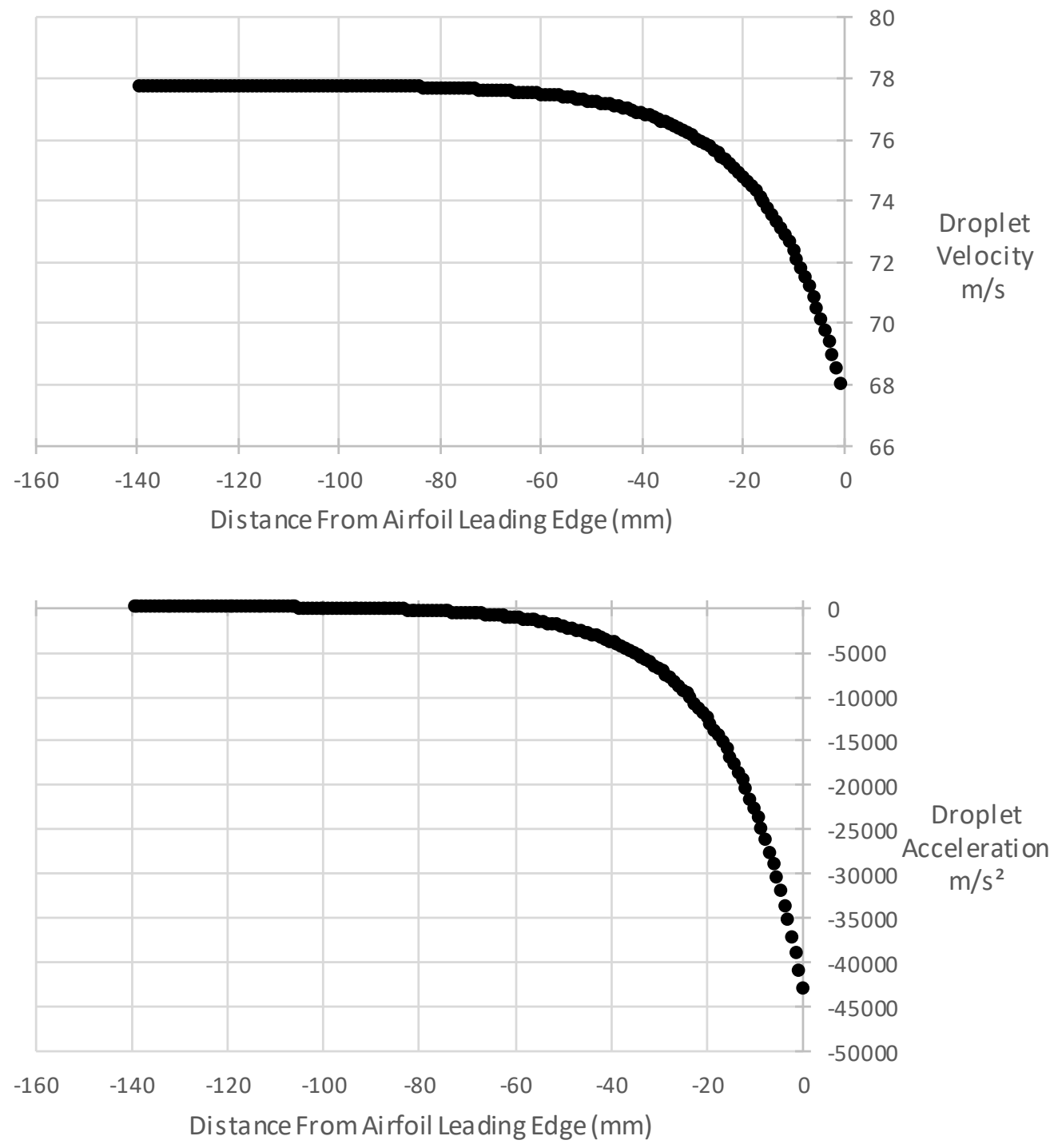

Figure 12: Droplet horizontal velocity (top) and acceleration (bottom) in the frame of reference at rest on the airfoil. Chamber temperature $=-20^{\circ} \mathrm{C}$, initial droplet velocity $=80 \mathrm{~m} / \mathrm{s}$, droplet diameter $=473 \mu \mathrm{m}$.

\section{Position of a Droplet with respect to the Frame of Reference at the Airfoil}

At a given location along the droplet path, the number of camera frames separating the droplet from the airfoil is equal to the frame number at which the airfoil hits the droplet minus the frame number at the given location of the droplet. Multiplying the number of frames separating the droplet and the airfoil by the time lapse between frames (1/frame rate) and by the airfoil speed gives the horizontal position of the droplet with respect to the frame of reference at the airfoil. Repeating the calculation for each droplet location gives the dis tance of the droplet along its horizontal path with respect to the leading edge of the airfoil. The main parameters in the experiment were calculated at each position of the droplet as it approaches the airfoil and with respect to the frame of reference located at rest on the airfoil. 


\section{E. Air Velocity at a given Droplet Location}

For an airfoil with the same geometry as the DBKUP 02 but scaled down $1 / 10$ in size $(0.047 \mathrm{~m}$ chord), the air velocity along the horizontal line ending at the stagnation point on the leading edge was measured experimentally with a Laser Droplet Velocimeter (LDV) at the INTA $0.3 \mathrm{mx} 0.2 \mathrm{~m}$ wind tunnel. The vertical axis in the plot records the air velocity divided by the free streamvelocity $\left(\mathrm{V}_{\text {air }} / \mathrm{V}_{\alpha}\right)$. The horizontal axis records the dis tance with respect to the leading edge of the airfoil divided by the chord $(\mathrm{x} / \mathrm{c})$. The experimental data was curve-fit and the resulting equation was used to calculate the air velocity at any given droplet position along its path. To calculate the position of the droplet using the curve-fit equation the value of the free streamvelocity is needed. For the frame of reference at rest with respect to the airfoil, the air free streamvelocity is the same as the velocity of the airfoil with res pect to the frame of reference at rest with respect to the test cell.

\section{F. Relative Velocity between the Droplet and the Air (Slip Velocity)}

Since at each droplet position along its path the horizontal velocity of the droplet and the velocity of the air are known, the relative velocity between the droplet and the air can be calculated. This velocity, $\left|V_{\text {air }}-V_{\text {droplet }}\right|$, is called the "slip velocity". The three velocities, the droplet, air, and slip velocities, are shown in Figure 13. The Reynolds number and the Webernumber can be calculated when the horizontal slip velocity at each location along the droplet path is known.

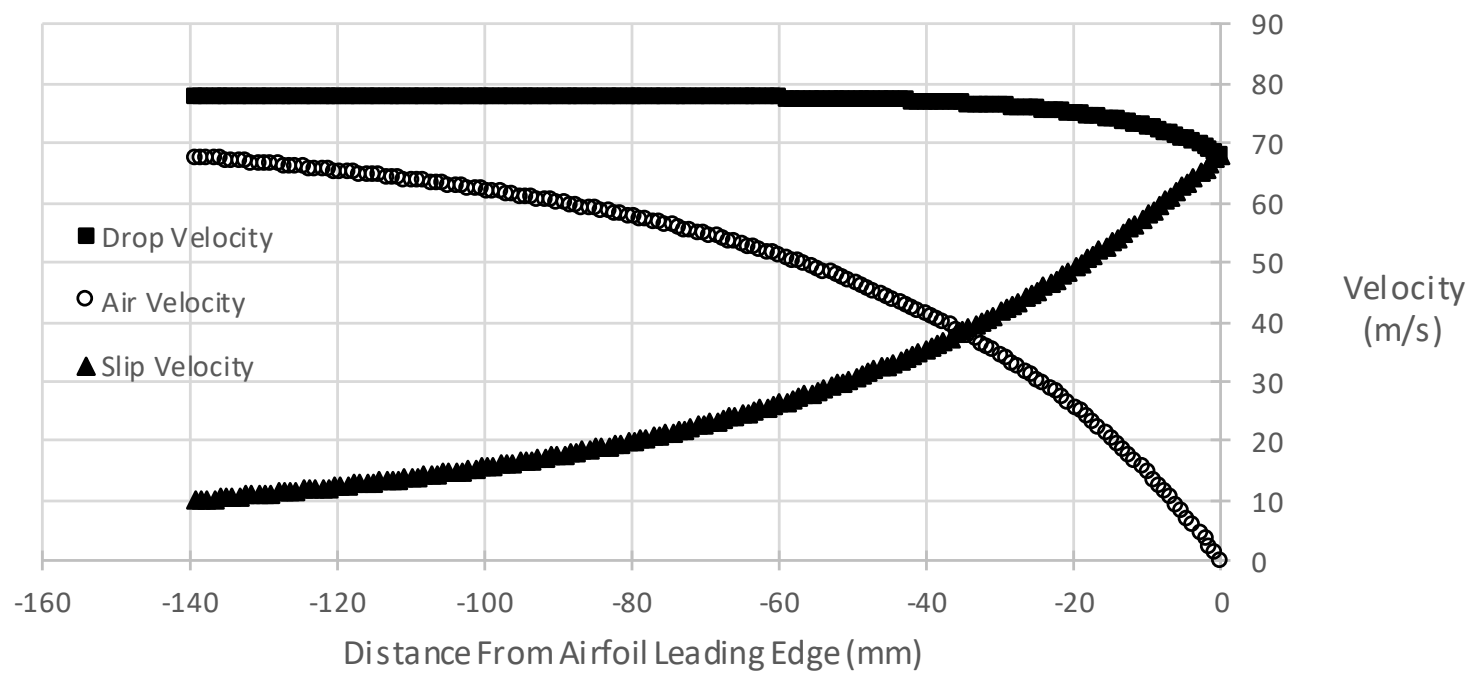

Figure 13: Droplet, air, and slip Velocity against distance from the leading edge of the airfoil. Chamber temperature $=$ $-20{ }^{\circ} \mathrm{C}$, initial dropl et velocity $=80 \mathrm{~m} / \mathrm{s}$, droplet diameter $=473 \mu \mathrm{m}$.

\section{G. Calculation of the Reynolds Number, the Weber Number}

The main parameters measured along the path of the droplet were the Reynolds number (Eqn. 2), the Weber number (Eqn. 3), and the Bond Number (Eqn. 4). All those parameters were measured with respect to the horizontal motion of the droplet. The droplets leave the monosize droplet generator and fall vertically at a constant speed between $3-4 \mathrm{~m} / \mathrm{sec}$ (measured during the experiment). There was no indication from the physical behavior of the droplet that the vertical velocity had an influence on the deformation of the droplet. The shape of the droplet during deformation corresponded to the response of the droplet to the horizontal velocity and acceleration. In all the measurements and calculations the vertical velocity was not considered.

The following are the definitions of the main parameters measured along the path of the droplet:

$$
\text { Reynolds Number } \quad \operatorname{Re}=\frac{\rho_{\text {air }}\left|V_{\text {air }}-V_{\text {droplet }}\right| D}{\mu_{\text {air }}}
$$


Weber Number

Bond Number

$$
\begin{array}{r}
W e=\frac{\rho_{\text {air }}\left(V_{\text {air }}-V_{\text {droplet }}\right)^{2} D}{\sigma_{\text {water/air }}} \\
B o=\frac{\rho_{\text {water }} D^{2}}{\sigma_{\text {water/air }}}\left(\frac{d V_{\text {droplet }}}{d t}\right)
\end{array}
$$

Where $D$ is the droplet diameter, $V_{\text {droplet }}$ is the droplet velocity, $V_{\text {air }}$ is the air velocity at the location of the droplet, ( $V_{\text {air }}-V_{\text {droplet })}$ is the slip velocity, $\rho_{\text {air }}$ is the air density, $\mu_{\text {air }}$ is the air absolute viscosity, $\rho_{\text {water }}$ is the waterdensity for the droplet, $\sigma_{\text {water/air }}$ is the water surface tension for the droplet. The Bond number was defined with res pect to the droplet acceleration.

Since the air and water droplet properties are known and the droplet diameter, the slip velocity and the droplet acceleration are measured or calculated along the path of the droplet, then the non-dimensional parameters can be calculated. The velocities and accelerations employed in the calculation of the parameters are for the horizontal direction.

\section{Results: Comparison of Supercooled and Room Temperature Droplets}

\section{A. Comparison of SupercooledDroplet and Room Temperature Droplet Data Collect in the AERTS Facility and in INTA}

For the comparis on of the droplet behavior, data from the tes ts done at INTA at room temperature are compared to data from the tests done in the AERTS facility at $-20^{\circ} \mathrm{C}$ chamber temperature. Although the airfoil speeds for the tests are different, $90 \mathrm{~m} / \mathrm{s}$ for INTA tests and $80 \mathrm{~m} / \mathrm{s}$ for the AERTS facility tests, the behavior of the droplets at a sip velocity of $60 \mathrm{~m} / \mathrm{s}$ is compared. The deformation (ellipse major axis/ellipse minor axis) and the Bond number of the droplets are plotted against the droplet diameter in Figure 14. The tests at INTA used droplet generator orifice sizes ranging from 500 to $1000 \mu \mathrm{m}$ while 200 , and $400 \mu \mathrm{m}$ droplet generator orifice sizes were used when testing in the AERTS facility. The lack of overlap in the datadoes not allow for proper comparisons to be made between the droplets in relation to their behavior. Yet, both the supercooled droplets and the roomtemperature droplets behave in a similar manner in that larger diameter droplets have higher deformation than smaller droplets. This can be observed via visual inspection. Two distinct sets of data related to the warm temperature case and the supercooled case arise in the comparis on presented in Figure 14, delimited by the line sketched in the graph.

Given that the described comparis ons are conducted at varying airfoil velocities, environmental temperatures, and droplet sizes, a conclusion regarding the effects of droplet supercooling on the deformation of the drops cannot be concluded. However, let it be assumed that the supercooling of the droplets has no effect on the droplet frag mentation. If this is the case, the Bond number would not change. Water surface tension is the main parameter in the Bond number that would vary with temperature. The as sumption of equal droplet deformation behavior for both environmental conditions assumes that the surface tension of the drops can be estimated to be constant given the small (less than 5\%) variation of water surface tension between room temperature and $-10^{\circ} \mathrm{C}$ water droplets. If this is the case, the Bond numbercan be plotted versus droplet size (Figure 15). The results suggests that there is a velocity effect between the two sets of data investigated (room temperature vs. supercooled droplets). To further explore the reas on for the difference between the two environmental conditions explored, the deformation of droplets at the same temperature for varying airfoil velocities (initial droplet velocity in the fixed frame) are compared in the next section. 


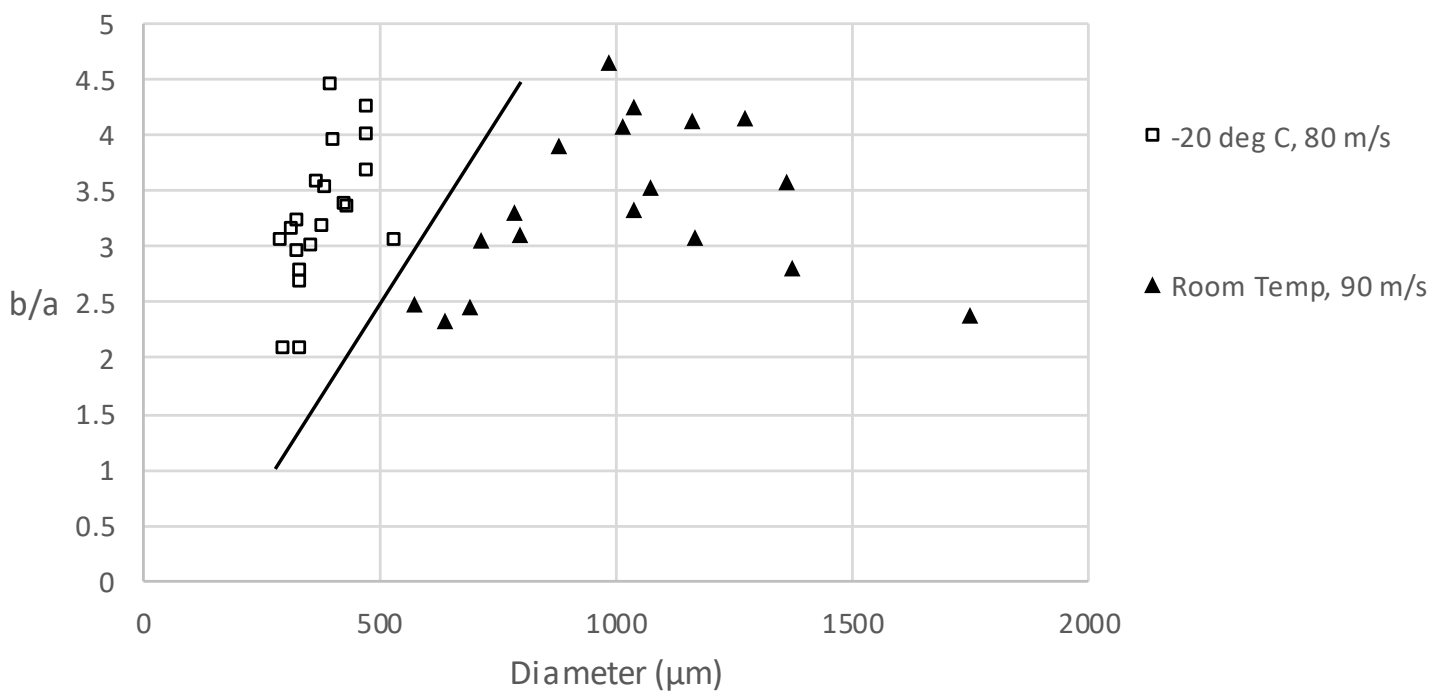

Figure 14: Droplet deformation against diameter at a slip velocity of $60 \mathrm{~m} / \mathrm{s}$.

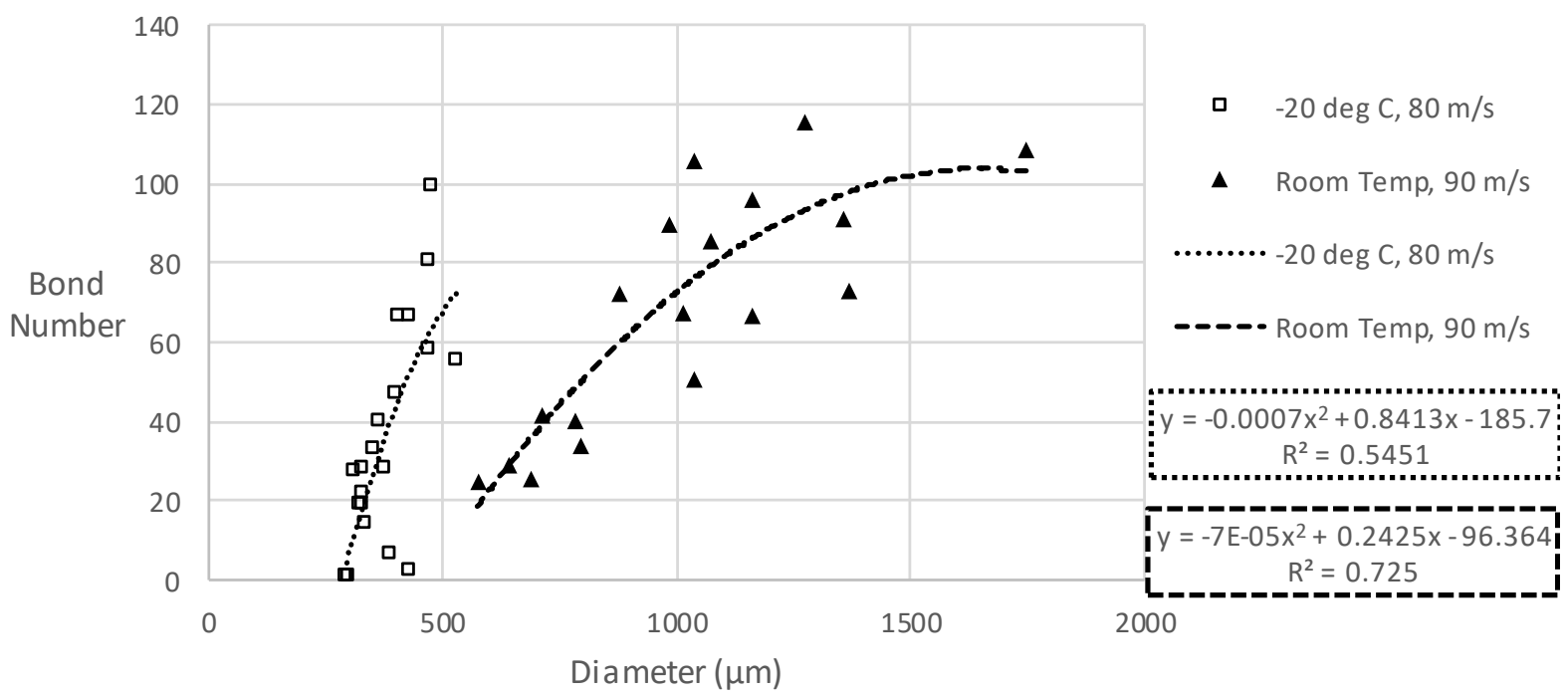

Figure 15: Bond number against droplet diameter at a slip velocity of $60 \mathrm{~m} / \mathrm{s}$.

\section{B. Effect of Initial Velocity on Deformation and Bond Number}

The deformation for the impacting drops tested at varying airfoil velocities plotted against the droplet diameter are shown in Figure 16. For these cases, the air temperature is $-20^{\circ} \mathrm{C}$ and the slip velocity is $50 \mathrm{~m} / \mathrm{s}$, but the initial droplet velocities related to the airfoil velocity in the rotating frame are $80 \mathrm{~m} / \mathrm{s}, 70 \mathrm{~m} / \mathrm{s}$, and $60 \mathrm{~m} / \mathrm{s}$. Such comparison allows for the investigation of the effects of velocity (initial and slip) on the droplet deformation. In the conducted correlation, trendlines were added to assist with the interpretation of the results. The slopes obtained are in agreement in magnitude, and there is no indication of a particular trend with variations in velocity (see Figure 16).

To investigate the effects of slip velocity, the deformation ag ainst droplet diameter for droplets with initial velocity of $70 \mathrm{~m} / \mathrm{s}$ and at four slip velocities at a chamber temperature of $-20^{\circ} \mathrm{C}$ is plotted in Figure 17. For an initial droplet velocity of $70 \mathrm{~m} / \mathrm{s}$, the droplet deformation slope at a slip velocity of $30 \mathrm{~m} / \mathrm{s}$ is 0.0011 . As the slip velocity of the drop increases to $60 \mathrm{~m} / \mathrm{s}$, the droplet deformation slope increases to 0.0065 . The same effect on the droplet deformation slope is observed as the slip velocity approaches the airfoil velocity. These results indicate that the ratio of the slip 
velocity to the initialvelocity affects the slope of the droplet deformation with respect to the droplet size. Given such variations in the droplet deformation slopes with respect to the droplet size, the initial droplet velocity and the slip velocity must be the same to investigate the effects of supercooling on droplet deformation. The following section compares the deformation of droplets with an initial drop velocity of $60 \mathrm{~m} / \mathrm{s}$ at a slip velocity of $40 \mathrm{~m} / \mathrm{s}$ at two varying environmental temperatures in an attempt to determine the effects of water temperature on such droplet deformation. The selection of mentioned slip and initial velocities ensures an equal ratio of these velocities for the investigation of the effects of supercooling on droplet deformation.

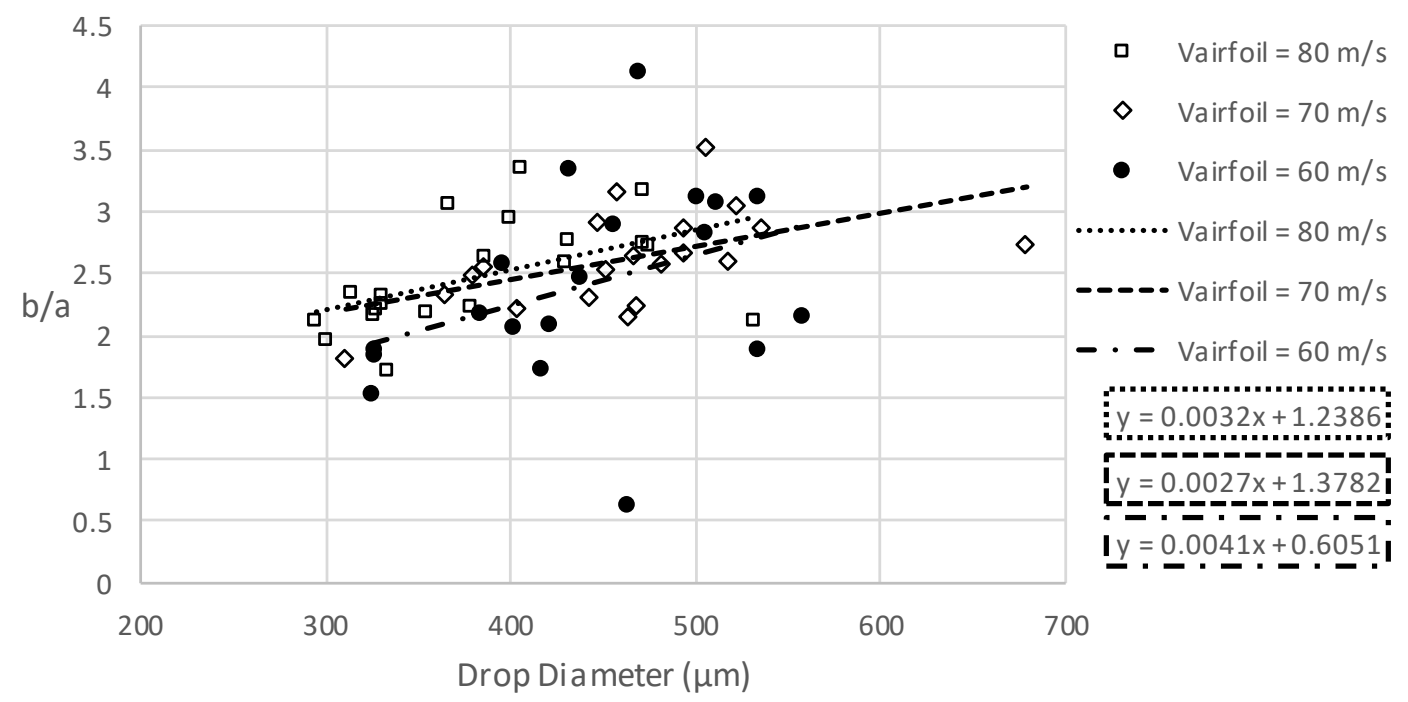

Figure 16: Droplet deformation against diameter at a slip velocity of $50 \mathrm{~m} / \mathrm{s}$ and chamber temperature of $-20^{\circ} \mathrm{C}$.

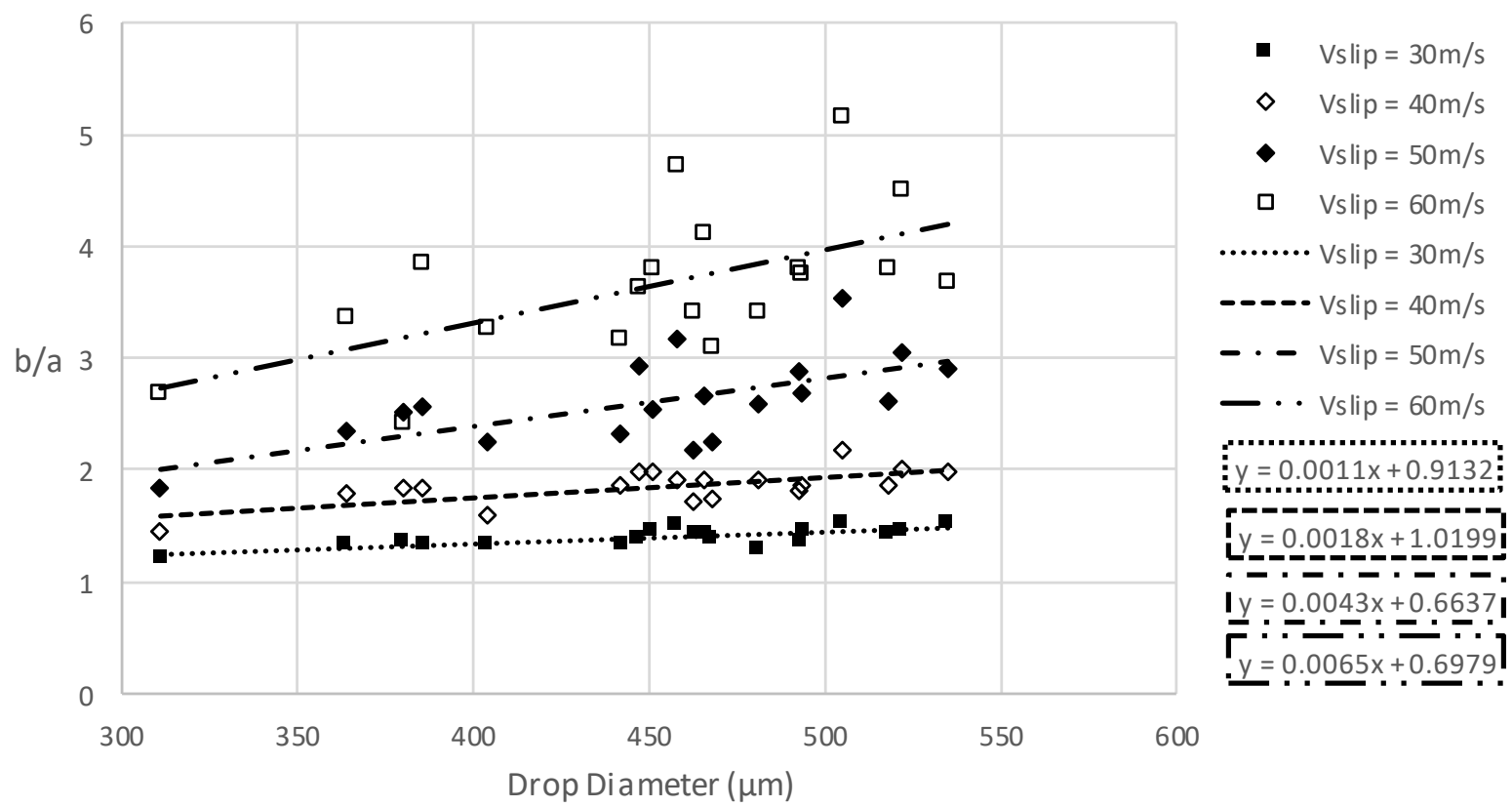

Figure 17: Deformation against droplet diameter for droplets with initial velocity of $70 \mathrm{~m} / \mathrm{s}$ and at four slip velocities, chamber temperature $=-20^{\circ} \mathrm{C}$. 


\section{Comparison of Supercooled Droplets and Room Temperature Droplet Data Collected in the AERTS Facility}

It has been establis hed that to determine the effects of droplet supercooling on its deformation prior to impact with an airfoil, identical slip and dropletinitial velocities must be compared. In addition, an effort is made to also compare data containing similar droplet diameters. The datacollected using an airfoil speed of $60 \mathrm{~m} / \mathrm{s}$ in the AERTS facility at $20{ }^{\circ} \mathrm{C}$ (room temperature) and $-20^{\circ} \mathrm{C}$ were used. In the mentioned tests the orifices used in the droplet generator were 150 and 200 micrometer diameters. The droplet deformation at a slip velocity of $40 \mathrm{~m} / \mathrm{s}$ is plotted below in Figure 18. The data in the figures overlaps as all of the droplets analyzed have similar diameters and trends indicating differences between warm droplets and supercooled droplets is not observed for the tested conditions. Based on these results, it is expected that the Bond number for the two environmental conditions should also agree, suggesting that the variation of the surface tension of the droplets does not cause a change in the behavior of the supercooled droplets. For this reason, it is assumed that the surface tension of the water is constant for both environmental conditions. If this is the case, it is expected that the Bond number for both temperature cases should follow an equal trend. The bond number for the room temperature case and the supercooled environment is plotted in Figure 19. Both the warm environment and the supercooled case follow an equaltrend. Square poly nomial fittings (sinceBond number is proportional to the square of the droplet diameter) were added, further showcasing the continuous trend between the results. The processed experimental datas uggests that supercooling has no effect on the particle deformation for the airfoil velocity investigated.

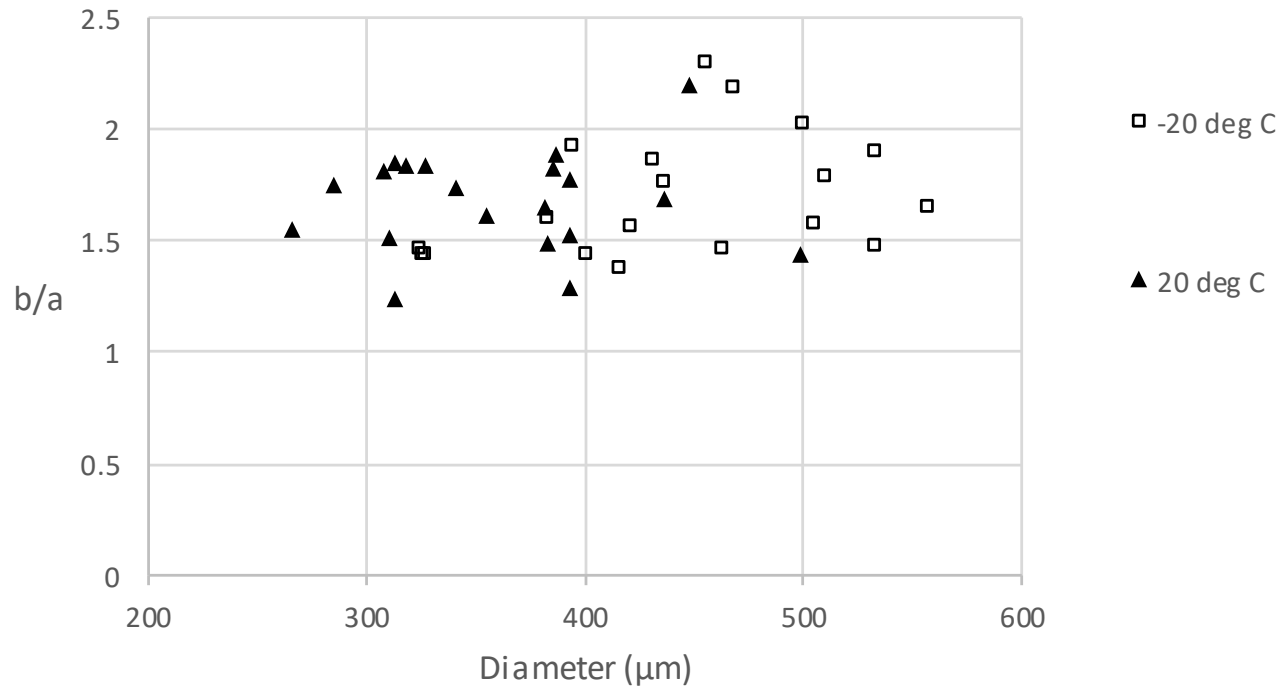

Figure 18: Droplet deformation against diameter at a slip velocity of $40 \mathrm{~m} / \mathrm{s}$ and initial droplet velocity of $60 \mathrm{~m} / \mathrm{s}$. 


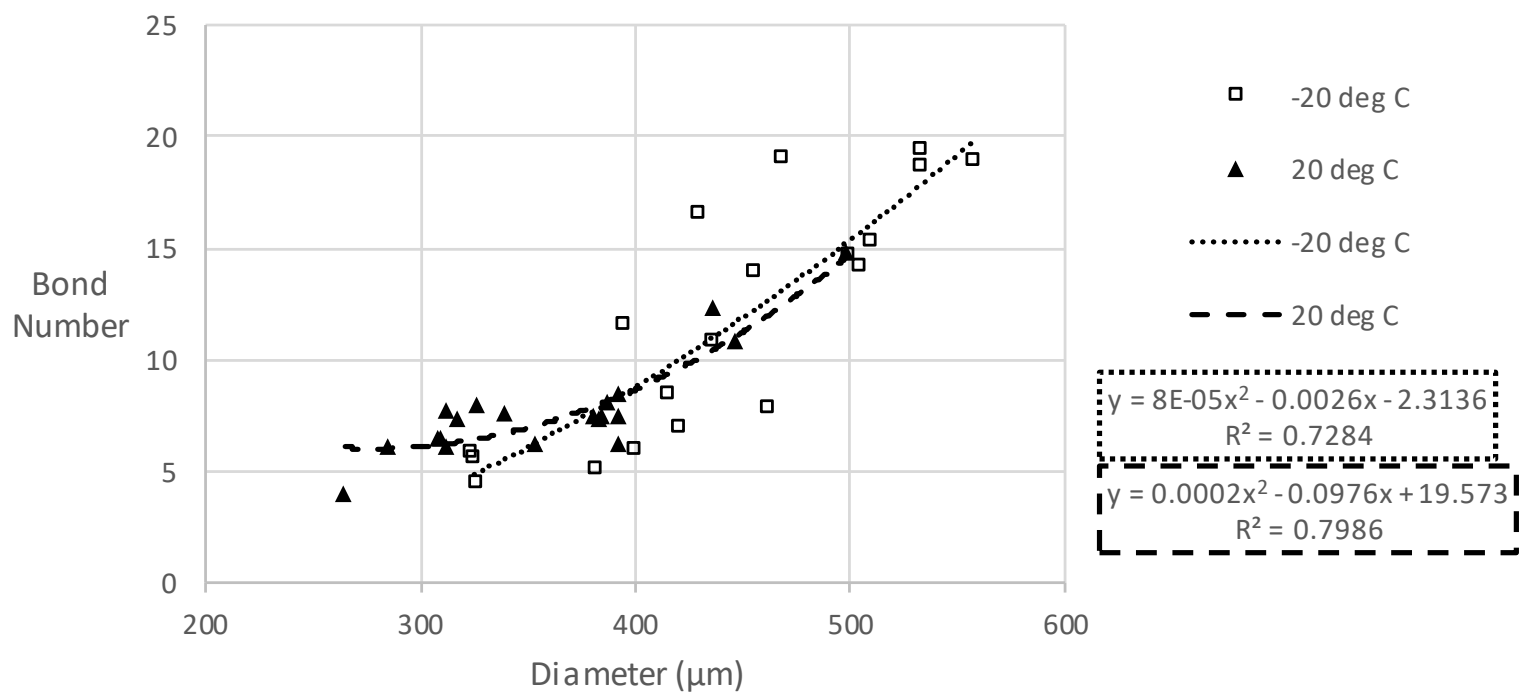

Figure 19: Bond number against diameter at a slip velocity of $40 \mathrm{~m} / \mathrm{s}$ and initial droplet ve locity of $60 \mathrm{~m} / \mathrm{s}$.

\section{Conclusions}

The purpose of the work presented here was to determine the effects of supercooling on the behavior of water droplets near the leading edge of an airfoil. The room temperature droplet data that was collected at INTA in Spain was compared to the data collected of supercooled droplets in the AERTS facility. The two sets of data could not be used in the comparis on of the behavior as the data did not overlap in terms of slip velocity/initial velocity ratios. Although the same slip velocity was compared, the ranges of droplet diameters and the airfoil velocity were different. It was demonstrated that to compare the effects of water supercooling on droplet deformation, the ratio of the slip velocity and the initial droplet velocity must be equal. To further explore the effects of droplet velocity on the deformation of droplets, experimental cases with constant slip velocity and varying airfoil velocity were investigated. A specific trend was not observed in the slopes of the data, but when the airfoil velocity was held constant and the slip velocity was varied, a clear effect on droplet deformation was observed. As the slip velocity approached the airfoil velocity, the slope of the data increased. For an airfoil velocity of $70 \mathrm{~m} / \mathrm{s}$ and a slip velocity of $30 \mathrm{~m} / \mathrm{s}$ the slope was 0.0011 and it increased to 0.0065 at a slip velocity of $60 \mathrm{~m} / \mathrm{s}$. This indicated that the ratio of the slip velocity to the airfoil velocity should be the same when comparing data to determine the effects of supercooling on droplet behavior.

A case with equal s lip velocity to initial velocity ratios was selected for roomtemperature and supercooled droplet conditions. The airfoil velocity was $60 \mathrm{~m} / \mathrm{s}$ and the slip velocity for both sets of data was $40 \mathrm{~m} / \mathrm{s}$. In these cases, the deformation of the supercooled droplet and that of the roomtemperature droplets did not present different trends for the limited range, weakly supercooled states of water droplets, tested. The similar behavior for both environmental conditions indicates that weak supercooling had no effect on particle deformation at the selected impact velocity. The as sumption of a constant surface tension value for the mentioned conditions was further supported by the equal trend of the Bond number obtained for supercooled droplets and roomtemperature ones.

\section{Acknowledgments}

The authors would like to thank Mr. Chris Lynch and Mr. Quentin Schwinn for their excellent work with the highspeed imaging system. We would also like to thank all of the AERTS facility research as sistants that were involved in the setup of the experiments and collection of data. Your help is very much appreciated. 


\section{References}

${ }^{1}$ Tan, J., Papadakis, M., and Sampaht, M. K., "Computational Study of Large Droplet Breakup in the Vicinity of an Airfoil", DOT/FAA/AR-05/42, Final Report, October 2005.

${ }^{2}$ Feo, Alex, Vargas, M., and Sor, S., "Rotating Rig Development for Droplet Deformation/Breakup and Impact Experiments Induced by Aerodynamic Surfaces", to be published in 2011.

${ }^{3}$ Vargas, M., Sor, S., and Magarino, A. G., "MechanismofW ater Droplet Breakup near the Leading Edge of an Airfoil," AIAA Paper 2012-3129, June 2012.

${ }^{4}$ Soltis, J., Palacios, J., Eden, T., and Wolfe, D., "Ice Adhesion Mechanis ms of Erosion-Resis tant Coatings,"AIAA Journal, Early Edition, June 19, 2014.

doi: $10.2514 / 1 . J 053208$

${ }^{5}$ Palacios, J., Han, Y., Brouwers, E. W., Smith, E. C., "Icing Environment Rotor Test Stand Liquid Water Content MeasurementProcedures and Ice Shape Correlation," Journal of the American Helicopter Society, Vol. 57, (2), April 2012, pp. 29-40.

${ }^{6}$ Bartkus, T. P., Struk, P. M., Tsao, J. and Van Zante, J. F., "Numerical Analysis of Mixed-Phase Icing Cloud Simulations in the NASA Propulsion Systems Laboratory," 8th AIAA Atmospheric and Space Environments Conference, AIAA, Washington D.C., 2016, AIAA 2016-3739.

${ }^{7}$ Otsu, N., "A Thres hold Selection Method from Gray-Level His tograms," IEEE Trans actions on Systems, Man, and Cybernetics, Vol. 9, No. 1, 1979,pp. 62-66. 
Table 1. DBKUP 002 Airfoil Coordinates

\begin{tabular}{cc} 
X-Coordinate & Y-Coordinate \\
\hline 1.0000 & 0.0000 \\
0.9989 & -0.0009 \\
0.9957 & -0.0014 \\
0.9904 & -0.0025 \\
0.9830 & -0.0042 \\
0.9735 & -0.0064 \\
0.9619 & -0.0089 \\
0.9484 & -0.0120 \\
0.9330 & -0.0155 \\
0.9157 & -0.0195 \\
0.8967 & -0.0240 \\
0.8759 & -0.0291 \\
0.8536 & -0.0347 \\
0.8297 & -0.0410 \\
0.8044 & -0.0479 \\
0.7778 & -0.0554 \\
0.7500 & -0.0634 \\
0.7211 & -0.0721 \\
0.6913 & -0.0815 \\
0.6607 & -0.0915 \\
0.6294 & -0.1019 \\
0.5976 & -0.1128 \\
0.5653 & -0.1240 \\
0.5327 & -0.1353 \\
0.5000 & -0.1466 \\
0.4673 & -0.1577 \\
0.4347 & -0.1683 \\
0.4025 & -0.1780 \\
0.3706 & -0.1870 \\
0.3393 & -0.1938 \\
0.3087 & -0.1985 \\
0.2789 & -0.2006 \\
0.2500 & -0.2007 \\
0.2222 & -0.1985 \\
0.1956 & -0.1943 \\
0.1703 & -0.1880 \\
0.1465 & -0.1797 \\
0.1241 & -0.1700 \\
0.1033 & -0.1584 \\
0.0843 & -0.1458 \\
0.0670 & -0.1318 \\
0.0516 & -0.1170 \\
0.0381 & -0.1007 \\
0.0265 & -0.0842 \\
0.0170 & -0674 \\
0.0096 & \\
0.0043 & 0.0498 \\
0.0011 &
\end{tabular}

$\underline{\text { X-Coordinate }}$

0.0000

0.0011

0.0043

0.0096

0.0170

0.0265

0.0381

0.0516

0.0670

0.0843

0.1033

0.1241

0.1465

0.1703

0.1956

0.2222

0.2500

0.2789

0.3087

0.3393

0.3706

0.4025

0.4347

0.4673

0.5000

0.5327

0.5653

0.5976

0.6294

0.6607

0.6913

0.7211

0.7500

0.7778

0.8044

0.8297

0.8536

0.8759

0.8967

0.9157

0.9330

0.9484

0.9619

0.9735

0.9830

0.9904

0.9957

0.9989

\section{$\underline{\text { Y-Coordinate }}$}

0.0000

0.0139

0.0310

0.0498

0.0674

0.0842

0.1007

0.1170

0.1318

0.1458

0.1584

0.1700

0.1797

0.1880

0.1943

0.1985

0.2007

0.2006

0.1985

0.1938

0.1870

0.1780

0.1683

0.1577

0.1466

0.1353

0.1240

0.1128

0.1019

0.0915

0.0815

0.0721

0.0634

0.0554

0.0479

0.0410

0.0347

0.0291

0.0240

0.0195

0.0155

0.0120

0.0089

0.0064

0.0042

0.0025

0.0014

0.0009 
Table 2: Test Matrix

\begin{tabular}{|c|c|c|c|c|c|c|c|c|c|c|}
\hline Date & $\begin{array}{c}\text { Run } \\
\text { Number }\end{array}$ & $\begin{array}{c}\text { Rotor } \\
\text { RPM }\end{array}$ & $\begin{array}{c}\text { Velocity } \\
(\mathrm{m} / \mathrm{s})\end{array}$ & $\begin{array}{c}\text { Orifice } \\
\text { Size }(\mu \mathrm{m})\end{array}$ & $\begin{array}{c}\text { Pressure } \\
(\text { bar })\end{array}$ & $\begin{array}{c}\text { Frequency } \\
(\mathrm{kHz})\end{array}$ & $\begin{array}{c}\text { Thermistor } \\
(\mathrm{k} \Omega)\end{array}$ & $\begin{array}{c}\text { Water } \\
\text { Temperature } \\
\left({ }^{\circ} \mathrm{C}\right)\end{array}$ & $\begin{array}{c}\text { Chamber } \\
\text { Temperature } \\
\left({ }^{\circ} \mathrm{C}\right)\end{array}$ & FPS \\
\hline $2 / 21 / 17$ & 1 & 376 & 60.01 & 200 & 1.00 & 14.00 & - & 15.90 & 20.00 & 140000 \\
\hline & 2 & 376 & 60.01 & 200 & 0.91 & 14.00 & - & 17.90 & 20.00 & 140000 \\
\hline & 3 & 439 & 70.06 & 200 & 0.89 & 14.00 & - & 17.20 & 20.00 & 140000 \\
\hline & 4 & 314 & 50.11 & 400 & 0.89 & 50.00 & - & 17.30 & 20.00 & 90000 \\
\hline & 5 & 376 & 60.01 & 400 & 0.90 & 50.00 & - & 17.30 & 20.00 & 90000 \\
\hline & 6 & 376 & 60.01 & 400 & 0.90 & 50.00 & - & 17.20 & 20.00 & 90000 \\
\hline & 7 & 439 & 70.06 & 400 & 0.90 & 50.00 & - & 17.20 & 20.00 & 90000 \\
\hline & 8 & 439 & 70.06 & 400 & 0.90 & 50.00 & - & 17.20 & 20.00 & 90000 \\
\hline & 9 & 439 & 70.06 & 400 & 0.89 & 5.00 & - & 17.20 & 20.00 & 150000 \\
\hline & 10 & 439 & 70.06 & 400 & 0.89 & 5.00 & - & 17.20 & 20.00 & 140000 \\
\hline $2 / 22 / 17$ & 1 & 313 & 49.95 & 400 & 1.18 & 5.00 & - & 2.50 & -20.00 & 90000 \\
\hline & 2 & 313 & 49.95 & 400 & 1.18 & 5.00 & - & 2.00 & -20.00 & 90000 \\
\hline & 3 & 313 & 49.95 & 400 & 1.18 & 5.00 & - & 2.00 & -22.60 & 90000 \\
\hline & 4 & 376 & 60.01 & 400 & 1.17 & 5.00 & - & 2.00 & -22.70 & 90000 \\
\hline & 5 & 376 & 60.01 & 400 & 1.17 & 5.00 & - & 1.40 & -22.70 & 90000 \\
\hline $2 / 23 / 17$ & 1 & 314 & 50.11 & 200 & 1.04 & 20.00 & - & 6.20 & -17.20 & 90000 \\
\hline & 2 & 314 & 50.11 & 200 & 1.21 & 20.00 & - & 1.60 & -21.40 & 90000 \\
\hline & 3 & 376 & 60.01 & 200 & 1.01 & 20.00 & - & 1.90 & -14.00 & 90000 \\
\hline & 4 & 376 & 60.01 & 200 & 1.01 & 20.00 & - & 1.20 & -14.00 & 90000 \\
\hline $2 / 24 / 17$ & 1 & 314 & 50.11 & 200 & 1.17 & 20.00 & 5.40 & 2.25 & -24.60 & 90000 \\
\hline & 2 & 376 & 60.01 & 200 & 1.16 & 20.00 & 5.16 & 3.22 & -21.00 & 90000 \\
\hline & 3 & 439 & 70.06 & $Z 00$ & 1.16 & 20.00 & 5.20 & 3.06 & -20.70 & 90000 \\
\hline & 4 & 439 & 70.06 & 200 & 1.16 & 20.00 & 5.28 & 2.73 & -21.20 & 90000 \\
\hline & 5 & 439 & 70.06 & 200 & 1.16 & 20.00 & 5.30 & 2.65 & -20.40 & 90000 \\
\hline & 6 & 470 & 75.01 & 200 & 1.16 & 20.00 & - & - & -20.40 & 90000 \\
\hline & 7 & 501 & 79.96 & 200 & 1.16 & 20.00 & 4.95 & 4.12 & -19.60 & 90000 \\
\hline & 8 & 500 & 79.80 & 200 & 1.14 & 20.00 & 5.12 & 3.39 & -19.00 & 90000 \\
\hline & 9 & 500 & 79.80 & 200 & 1.14 & 20.00 & 5.16 & 3.22 & 18.90 & 90000 \\
\hline
\end{tabular}

American Institute of Aeronautics and Astronautics 